\title{
Injection therapy and denervation procedures for chronic low back pain: a systematic review-clinical value?
}

\author{
Koen Van Boxem · Alex Cahana $\cdot$ Jan Van Zundert
}

Received: 4 August 2010/Accepted: 15 September 2010/Published online: 7 October 2010

(C) The Author(s) 2010. This article is published with open access at Springerlink.com

\begin{abstract}
"Injection therapy and denervation procedures for chronic low back pain: a systematic review" [1] evaluates the effect of two broadly defined treatment options for chronic low back pain. This forms indeed a burden to patients, society and physicians. Lack of knowledge of the causes of chronic pain and poor understanding of patient heterogeneity in pathophysiologic mechanisms and treatment response are a major explanation for unsuccessful trials [2]. Clinical research reaches the conclusion that a "mechanism-based" treatment approach in which therapeutic interventions target the specific mechanisms of a patient's pain is recommended [2].
\end{abstract}

Low back pain is divided into specific form due to fracture tumor, infection, etc and the aspecific form. We generally differentiate between degenerative diseases of the facet joints or of the intervertebral disc and radicular pain.

The described inclusion and exclusion criteria for the studies to be withheld in this systematic review [1]; however, suggest that the research group lacks the input of a

K. Van Boxem

Department of Anesthesiology and Pain Management,

Sint Jozefkliniek Bornem en Willebroek, Bornem, Belgium

A. Cahana

Department of Anesthesiology and Pain Medicine,

University of Washington Medical Center, Seattle, WA, USA

J. Van Zundert

Department of Anesthesiology and Multidisciplinary Pain

Center, Ziekenhuis Oost Limburg, Genk, Belgium

K. Van Boxem $(\square)$

Department of Anesthesiology and Pain Therapy,

St.-Jozefkliniek, Bornem and Willebroek,

Kasteelstraat 23, 2880 Bornem, Belgium

e-mail: koen.vb@telenet.be clinical experts who can provide information regarding the clinical diagnoses and the potential underlying mechanisms. In contrast, instead of following recent recommendations, pain syndromes with different underlying mechanisms are clearly mixed in the expectation to draw clinically relevant information on a therapeutic intervention. Moreover, also treatments with no indication in a clinical setting are analyzed, which troubles even more the evidence.

Under the heading injection therapy, injections of medication and proteolytic agents are considered and it is for the clinician strange to have epidural and facet joint injections discussed in the same line as local injections in spinal muscles. Moreover, the epidural injections are recommended for the management of subacute low back pain radiating into the leg. This means pain of a duration between 6 weeks and 3 months. Obviously because of the predefined criteria for inclusion of studies on patients with pain of duration of more than 3 months, the authors eliminate the most important trials on this treatment option. Of the three studies that are maintained for further analysis only the trial on targetted steroid placement deals with patients suffering radicular pain. Evidence-based practice guidelines [3] clearly indicate that the only indication for epidural corticosteroid administration is the management of subacute radicular pain. Epidural administration of local anesthetic may be used in surgery and postoperative pain control, but is not recommended for the management of chronic pain, mainly because of the short duration of action of the local anesthetic and the lack of mechanism/cause oriented mode of action.

The authors suggest a lack of clinical understanding and differentiation between degenerative disease of the facet joints and lumbosacral radicular pain because under the heading "zygapophysial joints (facet joints)" they also list 
the RCT comparing radiofrequency treatment adjacent to the dorsal root ganglion with sham intervention. This study was performed in patients suffering chronic lumbosacral radicular pain.

In a recent letter to the editor [4], a plea was made to include clinicians in the definition of the research question before starting a systematic review to obtain more clinically relevant information.

Open Access This article is distributed under the terms of the Creative Commons Attribution Noncommercial License which permits any noncommercial use, distribution, and reproduction in any medium, provided the original author(s) and source are credited.

\section{References}

1. Henschke N, Kuijpers T, Rubinstein SM, van Middelkoop M, Ostelo R, Verhagen A, Koes BW, van Tulder MW (2010) Injection therapy and denervation procedures for chronic low-back pain: a systematic review. Eur Spine $\mathbf{J}$

2. Dworkin RH, Turk DC, Peirce-Sandner S, Baron R, Bellamy N, Burke LB, Chappell A, Chartier K, Cleeland CS, Costello A, Cowan P, Dimitrova R, Ellenberg S, Farrar JT, French JA, Gilron I, Hertz S, Jadad AR, Jay GW, Kalliomaki J, Katz NP, Kerns RD, Manning DC, McDermott MP, McGrath PJ, Narayana A, Porter L, Quessy S, Rappaport BA, Rauschkolb C, Reeve BB, Rhodes T, Sampaio C, Simpson DM, Stauffer JW, Stucki G, Tobias J, White RE, Witter J (2010) Research design considerations for confirmatory chronic pain clinical trials: IMMPACT recommendations. Pain 149:177-193

3. Van Boxem K, Cheng J, Patijn J, van Kleef M, Lataster A, Mekhail N, Van Zundert J (2010) 11. Lumbosacral radicular pain. Pain Pract 10:339-358. doi:10.1111/j.1533-2500.2010.00370.x

4. Van Zundert J, Van Boxem K, van Kleef M (2009) Methodologists are not qualified to write clinical guidelines. Lancet 374:1326 (author reply 1327) 